Article

\title{
Participation, for Whom? The Potential of Gamified Participatory Artefacts in Uncovering Power Relations within Urban Renewal Projects
}

\author{
Teodora Iulia Constantinescu*, Oswald Devisch and Liesbeth Huybrechts
}

Architecture Department-Spatial Capacity Building Group, Hasselt University, B-3590 Diepenbeek, Belgium; oswald.devisch@uhasselt.be (O.D.); liesbeth.huybrechts@uhasselt.be (L.H.)

* Correspondence: teodora.constantinescu@uhasselt.be

Received: 1 April 2020; Accepted: 11 May 2020; Published: 12 May 2020

\begin{abstract}
When defining participation in urban renewal projects in a political sense, this concept implies the challenging of power relations in each of its dimensions while addressing the need for knowledge, action and consciousness. Knowledge is defined as a resource which affects observable decision making. Action looks at who is involved in the production of such knowledge in order to challenge and shape the political agenda. Consciousness is how the production of knowledge changes the awareness or worldview of those involved, thus shaping the psychological and conceptual boundaries of what is possible. This paper addresses these politics of participation via the use of gamification, and more particularly gamified participatory artefacts. We discuss how a 'good' participatory planning process implies rebalancing existing power relations via the redistribution of knowledge, consciousness and actions, and aims to operationalize this ambition through a game. We particularly focus on the urban renewal process of one particular case, namely the Vennestraat-one of the main commercial streets of the city of Genk (BE) and present a three year participatory mapping process that made use of three gamified participatory artefacts (i.e., socio-economic network mapping, gathering mental images and scenario games). After uncovering the complex field of power relations in the entrepreneurial street, we analyze the different types of relations/groups that emerge from this participatory mapping process. The paper concludes with an analytical framework that employs gamified participatory artefacts in order to map and understand power relations and the mechanisms that frame them.
\end{abstract}

Keywords: gamified participatory artefacts; scenario games; mental images; knowledge; action; consciousness

\section{Introduction}

According to Gaventa and Cornwall [1], a 'good' participatory planning process should (1) act as a platform for raising awareness on specific topics, knowledge redistribution on said topics and increasing consciousness among actors involved in urban renewal projects and should (2) argue extensively for the connection between knowledge and power and the maintenance of the strategic structural relationships between power and the knowledge monopolies. Gaventa and Cornwall [1] stress that the concepts of knowledge, action and consciousness are intertwined in any successful participatory process, which means successful from the perspective of politics. Knowledge is defined as a resource which affects observable decision making. Knowledge redistribution is then defined as the action of transferring this resource to all stakeholders involved in a participatory planning process. Action looks at who is involved in the production of such knowledge in order to challenge and shape the political agenda. Consciousness is how the production of knowledge changes the awareness or worldview of those involved, thus shaping the psychological and conceptual boundaries of what is possible. 
Games are increasingly put forward as tools to support such 'good' participatory planning processes as they arouse interest, motivation, and engagement by connecting personal attributes with real-world scenarios making the voices of 'others' heard in the planning process [2]. City governments started adopting serious gaming — games designed for a primary purpose other than pure entertainment-as a strategy to increase the quality and functionality of participatory planning processes ever since the 1950s [3-5]. 'Serious games will be considered a form of gamification because serious games are a specific sub-set of the meta-concept of gamification. Gamification encompasses the idea of adding game elements, game thinking, and game mechanics to learning content' [6]. Games are a critical tool towards uplifting creativity and enhancing human potential as it is pegged on the principle of increasing humans' engagement with various aspects of governance. Through devoted immersion, games provide individuals with required aspects of meeting objectives as set out in government goals and include their voice and everyday experiences of space in the planning discourse. According to the theoretical analysis in line with other related definitions, Harviainen and Hassan [2] describe games as environments that make appropriate use of motivational factors that often add value within the planning process. Kapp [6] refers to games as systems 'in which players engage in an abstract challenge, defined by rules, interactivity, and feedback, that results in a quantifiable outcome often eliciting an emotional reaction' while he considers that 'gamification is using game-based mechanics, aesthetics, and game-thinking to engage people, motivate action, promote learning, and solve problems'. Complementary to games, planners have also been adopting elements of games within their participatory processes [7]. All these approaches together are referred to as the 'gamification of civic participation' [8] and these are supported by gamified participatory artefacts. Gamified participatory artefacts are tools that employ ludic activities, gaming elements and/or game like mechanics [7]. They range from full-fledged games to gamified participatory activities to playful experiences $[6,8]$. In what follows we differentiate the concepts of serious games and gamification following the rationale of the case study that reflects the difference between applying actual serious games in an urban project and applying gamification mechanics to motivate and solve problems.

\section{The Political Role of Gamified Participatory Processes}

There is a shared epistemological critique among researchers regarding how power is ingrained and enhanced in the dominant or the positivist knowledge system of production. Conventional methods of research (e.g., questionnaires and surveys) are bound to reinforce the passivity of the groups regarded as powerless. Conventional methods of study achieve the reinforcement of passivity by making them the objects of the other groups' inquiry rather than being the subjects of theirs [9]. Knowledge, action and consciousness are the main elements to define resources, people that might act once the resources are identified and how they understand the environment and available possibilities to shape the political. If that what is considered as legitimate-or valid, conforming to the law or to rules for the greater-is in the hands of the dominant groups, the knowledge that they have disqualifies the other forms of knowledge that may be in their community [9]. Our hypothesis is that gamified participatory artefacts can enable spatial planners to understand these imbalances, while at the same time grasp opportunities to shift them. Gamified participatory artefacts can pose a challenge to the enhanced power inequities and can change the relationship between knowledge and power within the different groups [10]. Individuals' relationships with power and knowledge at the organizational level looks more in-depth at their interactions with their colleagues [11] and shapes a link that stresses how knowledge and power lead to or enhance one another in participatory planning processes [10]. Power is conceived as a connection of the domination, which signifies the importance of knowledge control and its production in the various aspects of life [12]. The dominant view of transformation in social elements has been characterized by the necessity of transitioning the structures deemed oppressive. The knowledge that appears to affect people's lives arises from a monopoly of the expert producers of knowledge.

The fun and psychological fulfilment individuals derive from gamified participatory artefacts stimulates civic engagement $[2,6,8]$. Even though a serious activity may demand significant involvement, 
the gaming aspect triggers positivity from an individual, thus realizing increased engagement that further leads to action. Heightened engagement remains the ultimate goal and a key objective of gamified artefacts within government institutions and the society as a whole. These artefacts are good tools to support action and stimulate consciousness as they are rule-based systems that support collective activities [3,6,8,13-15]. Game environments provide players with agency and act as knowledge transfer platforms [16-18]. Gamified participatory artefacts are a strategic tool for grasping dynamics between stakeholders involved in an urban renewal project as they can explore urban issues and can involve citizens. This translates into the potential of gamified participatory artefacts to incentivize for action and trigger consciousness about specific topics among participants. Equally, they can produce significant knowledge that can be transferred to other fields, which is one of the reasons the number of gamified artefacts addressing urban matters is continually growing $[8,19]$.

However, gamified participatory artefacts have not been always successful; they have been used and criticized as they failed to meet expectations. We argue that the failure of these artefacts is not so much linked to the tool itself but rather the result of a bad design of the participatory process within which the gamified artefact is used [20]. As we argued earlier, in a qualitative participatory process these artefacts need to act as a participatory media for interactive policymaking $[8,21,22]$ to articulate and rearticulate power relations and empower participants to take part in the debate. By creating fun in subjects that are not intended for playing, they help individuals connect with their engagement in a participatory process in an emotional way. Gamified participatory artefacts can enable humans to interact with their participatory engagements loyally and playfully, thus fostering increased dedication and commitment. When used well in a participatory process, the use of these artefacts can bring about a sense of agency [23]. Equally, gamified artefacts can be applied in both policymaking contexts and civil society, engaging with a variety of stakeholders as rule-based systems where one aims at achieving a predefined goal $[3,8,13-15]$. Gamified artefacts are built as enabling collective activities that act as platforms for players to relate to one another, adding a layer of complexity by enhancing interpersonal relations between participants in a process [24], increasing the fun aspect [25] and contributing to learning [16-18].

We propose to develop a participatory process that relies on a diversity of artefacts, each with specific goals. Within the context of this paper, we gave form to an overall participatory process in which gamified artefacts played a role-a participatory mapping process guided by one overarching research question: 'How can knowledge, action and consciousness around power relations in a given urban renewal process increase the success rate of a participatory process in achieving political goals?' Concretely, we are interested in 'What are the conditions for gamified participatory artefacts to act as enablers for interactive knowledge productive environments to uncover power relations?' and How can gamified participatory artefacts be used to allow debate on a clear agenda?

We explore possible answers to these questions by focusing on a case study, namely a ten-year urban renewal process meant to reinvent a social space: a retail street. We started a participatory mapping process to understand the urban renewal strategy and the role of the diversity of actors within it. The paper mainly aims to open a discussion on the politics of participation via the use of gamified participatory artefacts.

In the first section we discuss how a 'good' participatory planning suggests rebalancing existing power relations implying the redistribution of knowledge, consciousness and actions, which are quite abstract terms for spatial professionals to grasp. In section two, we continue by operationalizing these concepts through a participatory mapping process. We do so by focusing on the case of Vennestraat-one of the main commercial streets of Genk (BE). We then continue by introducing the participatory mapping process we undertook. In an attempt to bring in new voices in the participation process of the renewal urban process of the street, we tested the capacity of three gamified participatory artefacts (i.e., socio-economic network, mapping, gathering mental images and scenario games). In the third section, after uncovering the, complex field of power relations in the commercial street, we analyze 
the different types of relations/groups that emerge. We conclude with an analytical framework that employs gamified artefacts and serves to map and understand power relations.

\section{Literature Review}

\subsection{Participatory Mapping via Gamified Participatory Artefacts versus Knowledge, Action, and Consciousness}

Chambers [26] has argued for the usefulness of the participatory processes as an essential method for illuminating the realities of the 'others' as a basis for developing solutions against poverty and decision making. Participatory researchers have talked continuously about the large numbers of case studies that illustrate the importance of having new members in the decision-making panels and the research processes since they bring about new insights, concepts, and ideas that enrich the decision-making process and overcome the setbacks in society [26]. The arguments tabled by participatory researcher governments, and development experts have gone an extra mile to recognize the voices of 'others', which has popularized the democratic approaches with an eye on the reduction of poverty and other problems in the community [27]. The participation of 'others' in decision-making has also spanned the decisions affecting their livelihoods and environments.

Problem space and solution space, together with the large number of stakeholders involved, may burden the design process of urban renewal projects at urban scales. People in a given society, already affected by urban renewal projects, should take part in the decision-making process that addresses the democratization and the recovery of the experts' power [28]. In other words, the community as a whole (i.e., citizens, institutions, organizations) is involved, meaning that planning and designing become more and more complex and require more work on the ground. It thus becomes more difficult to scale solutions or develop theories and models. Many of the created solutions will only work in particular contexts and cannot be generalized. More valuable design insights could be achieved through methods for exploring complex situations and making them visible, sharable and debatable. Communication between designers and stakeholders via engaging gamified participatory methods that work as catalysts in bringing them together results in a better understanding of pressing urban issues. Participatory processes are an alternative form of knowledge exchange, nonetheless, to fulfil its liberating potential, participation has to address more than just one aspect of power which encourages mobilization and action over a long time to reinforce the alternative types of knowledge produced [29]. Actors' access to knowledge and participation in the production of knowledge, enables them to affect the social boundaries that in turn will allow them to conceptualize the various possibilities in their environment [30,31]. Control over other peoples' knowledge production is the first step towards the severe limitation of their possibilities, which can either be imagined by human beings or acted upon in line with the situation at hand. Participation implies challenging power relations in each of its dimensions by addressing the need for knowledge, action and consciousness [32]. Knowledge is defined as a resource which affects observable decision making. Action is concerned with who is involved in the production of such knowledge in order to challenge and shape the political agenda. Consciousness relates to how the production of knowledge changes the awareness or worldview of those involved, thus shaping the psychological and conceptual boundaries of what is possible [1].

In what follows we discuss how participatory mapping that engages gamified participatory artefacts can help uncover the role of these three concepts in a participatory process.

\subsection{Knowledge}

Indisputably, one of the most crucial contributions of participatory processes to social change and empowerment is in the knowledge dimension. More writers have backed up the argument by adopting a more democratic and open process where the new categories of knowledge based on the local realities are accentuated. Knowledge is constructed and embedded socially. From that perspective, knowledge is defined as a resource, which alters the visible power or observable decision-making. As such, the participatory mapping process we propose aims to uncover latent information and reveal 
'new' knowledge by portraying existing dynamics in a given context. With this exercise, we raise the question of:

- $\quad$ when is knowledge made visible and how can it be redistributed?

\subsection{Action}

Action focuses on the problem-solving process before progressing to the review of the knowledge that is generated from the process. The emphasis of the process of problem-solving lies in the discovery of knowledge that leads to the improvement of the situation rather than that, which contributes to the gaining and retention of knowledge without utilizing it [33]. As the main aim of obtaining knowledge is to utilize it to address particular societal problems, the action is also taken to change the circumstances. Action is defined as the consideration of the individuals involved in the production of knowledge to challenge and shape political power. In this case, the action is recognized as the hidden power [34] that we aim to uncover via a participatory mapping process guided by two research questions:

- how can gamified participatory artefacts make power relations visible?

- how can gamified participatory artefacts involve the voices of 'others' in the participatory process?

\subsection{Consciousness}

Consciousness is explained as the force that focuses on the production of knowledge to change the worldview awareness and the people involved and thus to shape the conceptual and psychological limits of the possibilities in the world [34]. Consciousness is suggested to be the invisible power that the participatory mapping process we propose will bring to fore by indexing images people have about certain places/topics. This process makes room for reflection on existing power relations in a given project, thus allowing for new proposals. In this case, the participatory mapping process is guided by the following question:

- $\quad$ when are power relations challenged?

\section{Case Study}

We explore the potential of gamified participatory artefacts in uncovering power relations with the help of a case study. The case study is an urban renewal project, namely the reconversion of a commercial street, the Vennestraat, located in the city of Genk (BE). In order to understand the dynamics of the urban renewal process of Vennestraats' refurbishment, we first analyze available planning and policy documents, minutes of meetings and reports of events on the history of power relations within the street (e.g., Rapport Rasterstad Genk, Global Visie stad Genk, G360 report). On the basis of this review we formulate a series of hypotheses that we later check by conducting a participatory mapping process in Vennestraat relying on three types of gamified artefacts as enabling tools: (1) a tool to visualize the socio-economic networks of proprietors from the street, (2) mental images and (3) games.

\subsection{Genk: A City in Transition}

Genk has an industrial historical background, strongly related to the Walloon mining towns in the Sambre-Meuse valley. The city is in full transition. For years characterized by the coal mines, later on, strongly leaning on a rather traditional automotive industry (e.g., Ford and its network of suppliers), Genk is currently realizing an impressive transformation towards a creative knowledge economy. This change is the result of a policy that has been consistently developed over the past ten years based on one clear long-term vision-strengthen local communities via the creation of jobs. On the basis of a thorough analysis, several 'clusters' were defined around which the city develops its economic policy: (1) the gaming sector, with some companies focusing primarily on 'serious games' (computer games with an emphasis on communication and education), (2) the energy sector and (3) the health economy sector. Each of the above spearheads receives its physical translation in Genk through thorough infrastructure 
projects on and around the old mining sites of Winterslag (e.g., C-Mine) and Waterschei (e.g., Energyville). $\mathrm{C}$-mine is a cultural hub that functions in the buildings of the former mining cluster. Interestingly, the intended dynamics and the action radius extend beyond this place in itself. The urban projects in Genk can mainly be characterized as the rectification or designation of remnants from earlier developments (i.e., the disused mining sites), backdrops for an ambitious conversion or redevelopment project. The C-Mine reconversion project is praised nationally as a real quality leverage project that gives Genk a new look and points the way to new development steps. Together with a thorough refurbishment of the city center, the lack of an attractive historic-economic city center, these projects are having a substantial impact on the general view and the experience of the 'urbanity' of Genk. As a catalyst for this economic transformation, the city authorities are aiming for a secure future-targeted basis, which should lead to sustainable growth and job creation, for both high and low skilled people. Genk is one of the pioneers in Flanders when it comes to planning and implementing strategic urban projects. This has been a learning process for the city that has certainly not always gone smoothly, but the results can be seen and it is expected that important steps will be taken in the near future. One such example is the G360 project: a civic brainstorming event organized by the city of Genk a few months after the 2012 municipal elections. The aim was to allow residents to directly formulate their opinion and ideas about the future vision for Genk. Almost 500 participants gave more than 2000 ideas within eight predefined themes, which were incorporated in a clear report. This report helped form the basis for the multi-year policy plan that the new city council presented at the end of 2013. But more than just a way to ask citizens about their policy priorities, the G360 is an example of innovative citizen participation that also stimulated political involvement and highlighted Genk as a successful society lab of very different population groups. Genk's multiculturalism is an asset; from its 65,000 inhabitants, $48 \%$ are of non-Belgian origins- $15.7 \%$ Turkish, $14.6 \%$ Italians, $5.4 \%$ East-Europeans, 5.3\% Moroccans. In addition, within the migrant community, there is a strong entrepreneurship and economic dynamism concentrated in one of the commercial streets of the city-the Vennestraat street.

The Vennestraat is a segment in the network of local stone roads that can best be described as a real center street with a lively and diverse program and an adapted section (Figure 1) and offers a pleasant space for cyclists and pedestrians. However, such streets remain an exception within Genk. It is an alternative center for the residential areas around it and one of the poles of the city (Figure 2). Figure 2 shows the main destinations in Genk by program. With the C-mine opening in the vicinity, Vennestraat too experienced a shift and makeover not only in the urban refurbishment policy but the economic one as well. The street became more visible due to the increased traffic to and from C-mine and the administration body soon realized the two (C-mine and Vennestraat) would function better together, as a whole as opposed to as two different entities (a cultural hub and commercial street). The street became an interesting site for researchers working closely with the city of Genk to find the best scenario for Vennestraats' development. Vennestraat offers a particular contextual lens as it is a street situated close to the city center (10 minutes away) and its space is of everyday inhabitation rather than of symbolic occupation. 


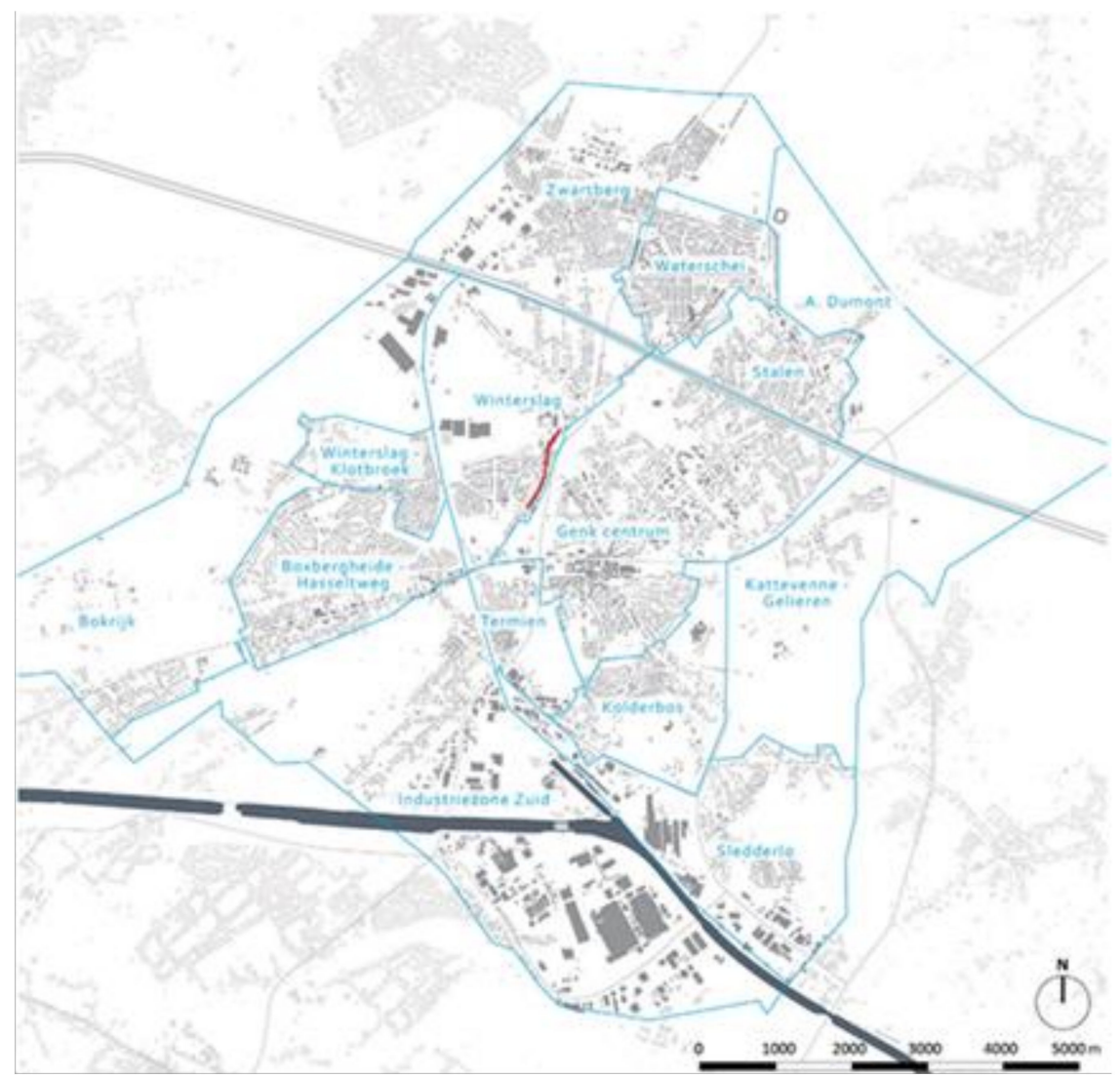

Figure 1. Position of the Vennestraat street (in red) in the city Genk. Source: Rapport Rasterstad Genk, BUUR, 2014.

\subsection{The Urban Renewal Process of Vennestraat}

Vennestraat hosts 76 dwellings, among them, the old cinema building (now abandoned), two supermarkets, a tattoo studio, an art gallery and 68 retail shops. The street is famous for its HoReCa segment that offers a varied pallet of products (e.g., from Turkish, traditional Italian ones, to handmade art deco jewelry). With the purpose of mapping Vennestraats' urban renewal process we analyzed a series of public reports and urban development plans issued by the municipality, the streets' development strategy and steps taken by the administration. Accordingly, we conducted five in-depth interviews with city officials responsible with the process for the past ten years and more than twenty in-depth interviews with citizens living in the area that witnessed the progressive changes. We did so in order to enlarge the spectrum and understand how this process was perceived from different angles, by different actors involved. The analysis revealed that trade, hospitality and tourism are an important employment engine that ensures an urban experience in Genk. The administration took the initiative for the (re)development of shopping and catering areas. As stated above, the city has no historic city center and therefore misses catering in the center. The city government is changing this through subsidies and pays attention to the various urban trade centers, which are complementary to the abovementioned clusters. Since the arrival of C-mine (i.e., the cultural hub housed in the former mining buildings), the Vennestraat has been re-branded as the 'street of the senses' [35]. It is mainly immigrant entrepreneurs who have opened businesses here. Some of the shops have existed there since the mines, passed on from one generation to another. Based on the streets' history, the municipality uses 'multiculinarity' in trade and hospitality as an asset using, among other things, a 'max of the mix' marketing strategy [35]. 


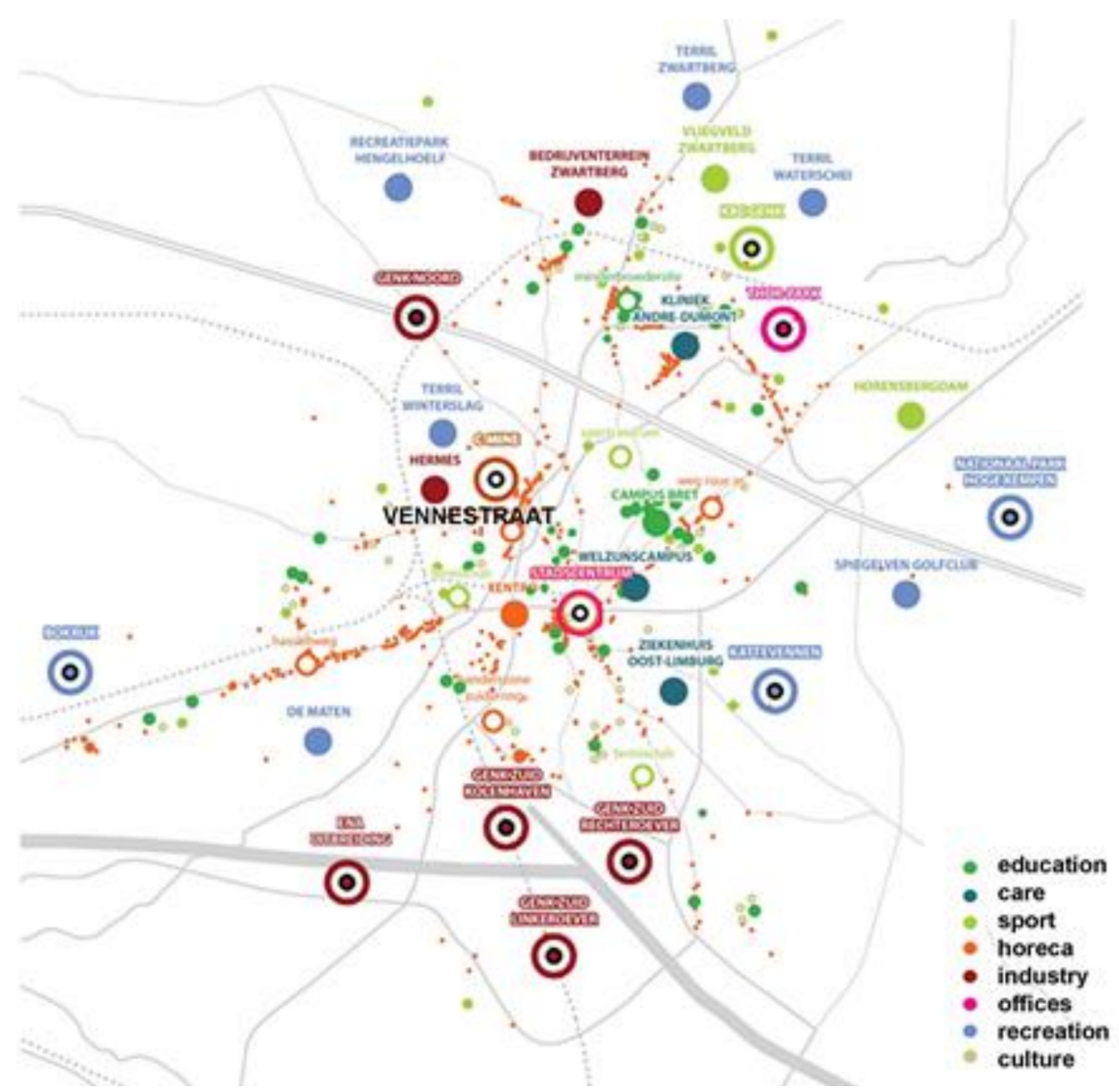

Figure 2. Vennestraat street and the city landmarks. Source: Rapport Rasterstad Genk, BUUR, 2014.

Over the past decade, the municipality has consciously played an active managerial role as an engine for the economic development of the street. Vennestraat is a $3.5 \mathrm{~km}$ long street with a compact commercial segment. This commercial part of the street, located in the vicinity of the cultural hub, makes the subject of this research. During the heavy mining period, Vennestraat was known for its shops. Back then, shops on the street addressed mainly the workers from the mines and started appearing close to the main buildings and extraction site, what is now known as C-mine. They were small family businesses (e.g., shoe repairing services, small butchery, carpentry). The majority of entrepreneurs on Vennestraat were of Turkish origin. The street was perceived as a dirty place, unsafe and hectic due to its connection to the mine [35]. Soon after the mine closed, the image of the street started to change as the city invested a lot in its refurbishment and in strategies to shift peoples' perceptions about it. The municipality created the neighborhood management department [36]. A neighborhood manager was appointed to each neighborhood and had a mediating role. This system still functions; the neighborhood manager is responsible for reporting to the administrative body the problems identified in the area, peoples' needs and objections and informing the community about eventual future projects or developments the city has planned in their vicinity that might affect them. Vennestraat has a street manager that has the 'sole' responsibility to improve the streets' image. The city made a development plan, an economic strategy on how to transform Vennestraat from a dangerous place to a 'multi-cultural cuisine hub'. The strategy started taking form at the same time Ford was announcing the intention to close the car factory (around 2003), an intention that was acted upon in 2014. Ford opened the factory little after the mines closed and, for over fifteen years, it was the primary employer in Genk, providing over 20,000 jobs. After it closed, in 2014, Genk faced a major unemployment crisis. This economic change was a turning point for the administration, shifting from an entrepreneurial urbanism approach to one of 'supporting local production'. As such, in 2010, Genk began the urban renewal process intending to create a brand for Vennestraat. 


\subsection{Urban Space}

The first intervention on the street was to change the pavement, enlarge the sidewalks and change the parking policy (from perpendicular parking to parallel, limiting as such the number of parking spots). The long-term goal was to restrict car access as much as possible and allow more space for terraces and outside sitting/resting places. This decision was taken by the administrative body with no prior public consultation, following international trends of high streets refurbishments. Demand for renting empty shops on the street started to arise mainly from the Italian community bringing about change with their variety of food-related businesses from shops to restaurants. The municipality saw it as an opportunity to build upon and set into place the idea of Vennestraat, 'the street of senses'.

\subsection{Subsidies}

As such, any entrepreneur that would want to open a food-related shop was welcome to do so in Vennestraat. The city of Genk set in motion a subsidy strategy [36]: proprietors seeking to open a shop were supported to turn towards Vennestraat, as the renting prices were lower and the municipality would give a starting subsidy for those who would revive one of the empty shops. Gradually, businesses run by other minorities started appearing, and the street became a hub of international cuisine (e.g., Turks, Moroccans, Italians, Polish, Greeks, Belgians). The diversity of cultures was present not only through the different products that one could find on the street but in the way shop owners presented and ran their shops. Clashes started appearing fueled by the different backgrounds of the proprietors, including cultural and religious beliefs [36]. The administration had a clear idea of how to address these tensions and how the street should look in order to make it thrive as a space of economic production, leisure, cultural mixing and cohabitation.

\subsection{Markets and Festivals}

The city hall, through the street manager, started organizing events to bring people together and strengthen the community by offering a platform where different cultures could cohabit. Sunday markets started to be organized by the city as a third intervention of the urban renewal process, closing the street for cars. Music and food festivals came next as a medium of advertising and 'getting to know your neighbor' proprietor (during these events, each shop owner can participate and sell products/food from his/her shop).

\subsection{Call for Projects}

Consequently, the municipality put out a call for projects seeking a team of architects that would design a layout for the street (e.g., window fronts, menus, shop signs, etc.). The intention was to have a homogenous image for all shops [35]. Ten teams applied for the call for projects and one was selected by the committee composed of members from the economic department, urban development department and the street manager. The winning team would later design a manual of 'good practices', a 'how-to' improve the image of your shop handbook together with city officials [36]. Proprietors were presented with the ideas and again, subsidies were offered if they decided to make changes according to the 'manual'. The administration went a step further and made it a policy: one can only make specific changes that impact the outside space in front of his/her shop and/or the building if discussed with the street manager and approved by the municipality [36]. The street manager helped proprietors to organize in an association to better relate to the administrative body. The association is run by five proprietors and has around 45 members from a total of 76 shops [36]. All dialogues are between the street manager and the five representatives which later inform the rest of the shop owners on the events and decisions to be taken. They meet once a month and discuss different topics; however, the final decision is made by the city administration. Besides the obvious benefits, the association gave a voice to a handful of proprietors that would come to relay the image given by the street manager to the rest of the shop owners. 


\subsection{The Outcome}

As a result of this process, the street became a hot spot of the city and renting prices went through the roof. Small proprietors that were the driving force of trade on Vennestraat at the beginning were now pushed out to the poorer parts of the city making room for a strong gentrification process [35]. As 'cities have the capability of providing something for everybody, only because, and only when, they are created by everyone' [37], we stress the importance of including all voices in urban renewal processes. Given the intrinsic relation between spatial and economic developments and their impact on social life, refurbishing a street such as the Vennestraat in Genk (BE) requires a multi-actor perspective that also takes into account the marginalized voices of the community, crucial in making a change towards more sustainable development. As such, we mapped the power relations in the street in order to understand the potential of reinforcing this multi-actor perspective. We did so by organizing a participatory mapping process relying on a tool to map socio-economic networks, mental maps and scenario games.

\section{Methodology}

\subsection{A Participatory Mapping Process}

The review of policy documents suggests that the urban renewal project introduced a series of shifts in power relations. In order to act upon these shifts, we started a participatory mapping process during which we invited the proprietors from Vennestraat street to collectively try to map and understand the current social and economic dynamics in the street. In order to support this mapping process, we developed a series of gamified participatory artefacts: a socio-economic network tool, mental images and two scenario games (Figure 3).

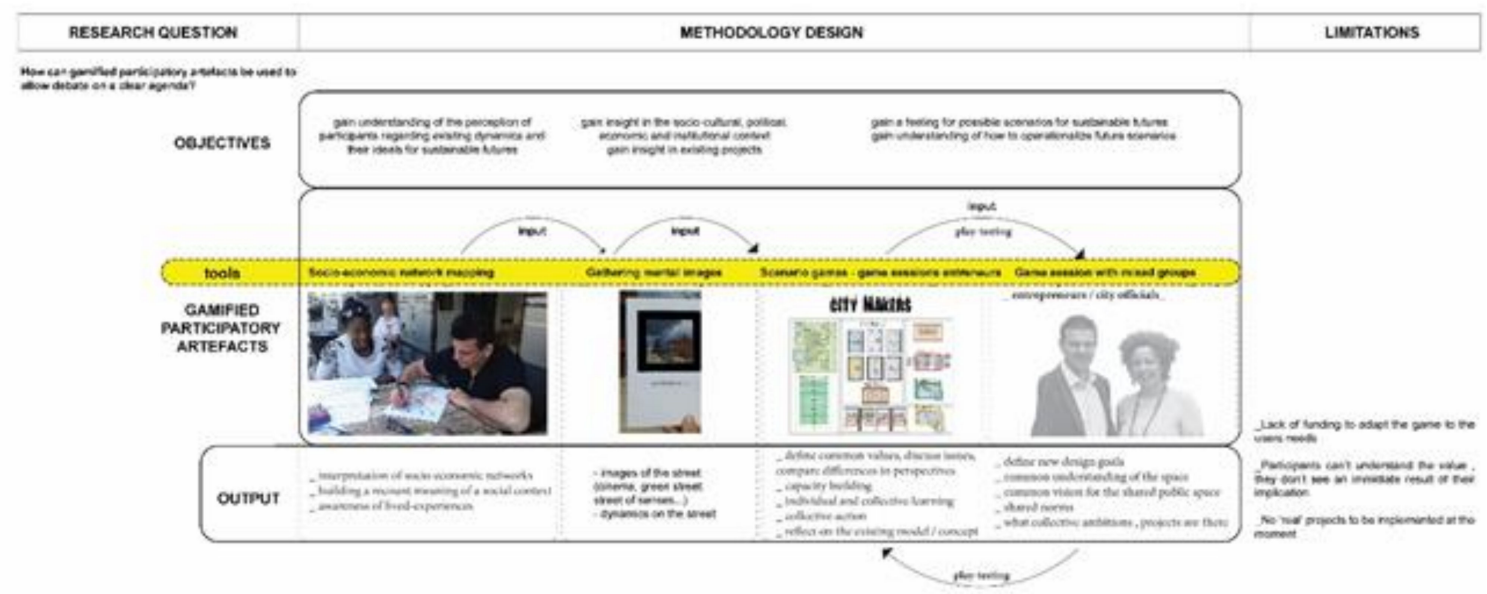

Figure 3. Participatory mapping process methodology.

Before starting with the participatory mapping activity, a long period of building trust with shop owners was necessary (six months); due to the extensive research projects conducted on Vennestraat, shop owners were reluctant to engage and invest time in new activities that could not guarantee an immediate gain. During the first two years of research, the period when we were maintaining an active dialogue with proprietors, they started opening up about different problems, needs and frustrations they were encountering regarding the refurbishment of the street. Trust was building up slowly and they were identifying with our research. As the relation became stronger, shop owners started to allocate time for testing out the first game artefact we were proposing, namely the socio-economic network mapping tool. We adapted this tool after the tool John Fass [38] used in his Everybody needs Somebody project.

Different types of knowledge came to the fore (e.g., knowledge about the different local/international networks, economic aspects, social dynamics). Based on these initial findings we did a second iteration, 
this time enlarging the target group to not only proprietors but passers-by/'consumers' of the street as well. In this iteration we introduced a second gamified artefact, namely mapping mental images. Gathering more than a hundred and fifty mental images from both groups uncovered the particularities of the dynamics on the street and the participatory process conducted so far became evident. A clear division between the economic part (the segment of the street closer to the C-mine) and the south part of the street, underlined the marginalized groups of proprietors. Equally, tensions among proprietors' sub clusters from the economic part were revealed. In order to further explore and address these tensions and the challenge to introduce all voices in the process of refurbishing Vennestraat, we proposed scenario games to act as a platform for collective reflection over priorities on the street. The methodology was received with enthusiasm at first by most of the shop owners. However, at this time we had to pause the research. Due to external factors, the research was put on hold for nine months after the socio-economic network mapping exercise and mental images gathering, before employing games. Prior to this break, we were constantly present in the street, nourishing the interaction with proprietors and maintaining the dialogue. When resuming, after an absence of nine months, we found a very distant public, quite negative and pragmatic. The power relations that had slightly opened prior to the 'break', had closed. Proprietors were more distant this time around. We observed an interest in trying the games from the shops association members and the street manager but we could not fully re-establish the connection with all entrepreneurs we were in contact with at the beginning of the process. As we were constrained to leave the participatory process abruptly, there was no continuation of using the tools nor any feedback to keep proprietors engaged.

In what follows we will first describe the artefacts and then discuss how they had impact on the participatory process focusing on the concepts of knowledge, consciousness and action. We do so by addressing, in each case, the questions defined in chapter 2.

\subsubsection{Socio-Economic Network Mapping}

The first gamified artefact used was strategic and focused on addressing proprietors in their expert roles. In order to uncover the complex field of power relations in this entrepreneurial street we started by mapping the existing dynamics between shops. Relational maps have been used since the seventies in order to capture the diversity of links [39,40]. We were interested to reveal social and economic networks in order to get a grasp on the existing latent knowledge. Equally, we aimed at debating the concept of consciousness about this knowledge among shop owners in the refurbishment process of the Vennestraat street. As John Fass [38] did in his Everybody Needs Somebody project, we used an A3 foam board, pins and rubbers of different colors and asked participants to trace their shops' network. The pins were divided into different categories: blue was used to represent employees, white for human customers, for nonhuman customers—other shops—we used pink pins and green ones to represent providers. Red pins were used to position the shop for which the network was portrayed. The rubber bands marked the connections between the different actors involved in one specific network (Figure 4). 


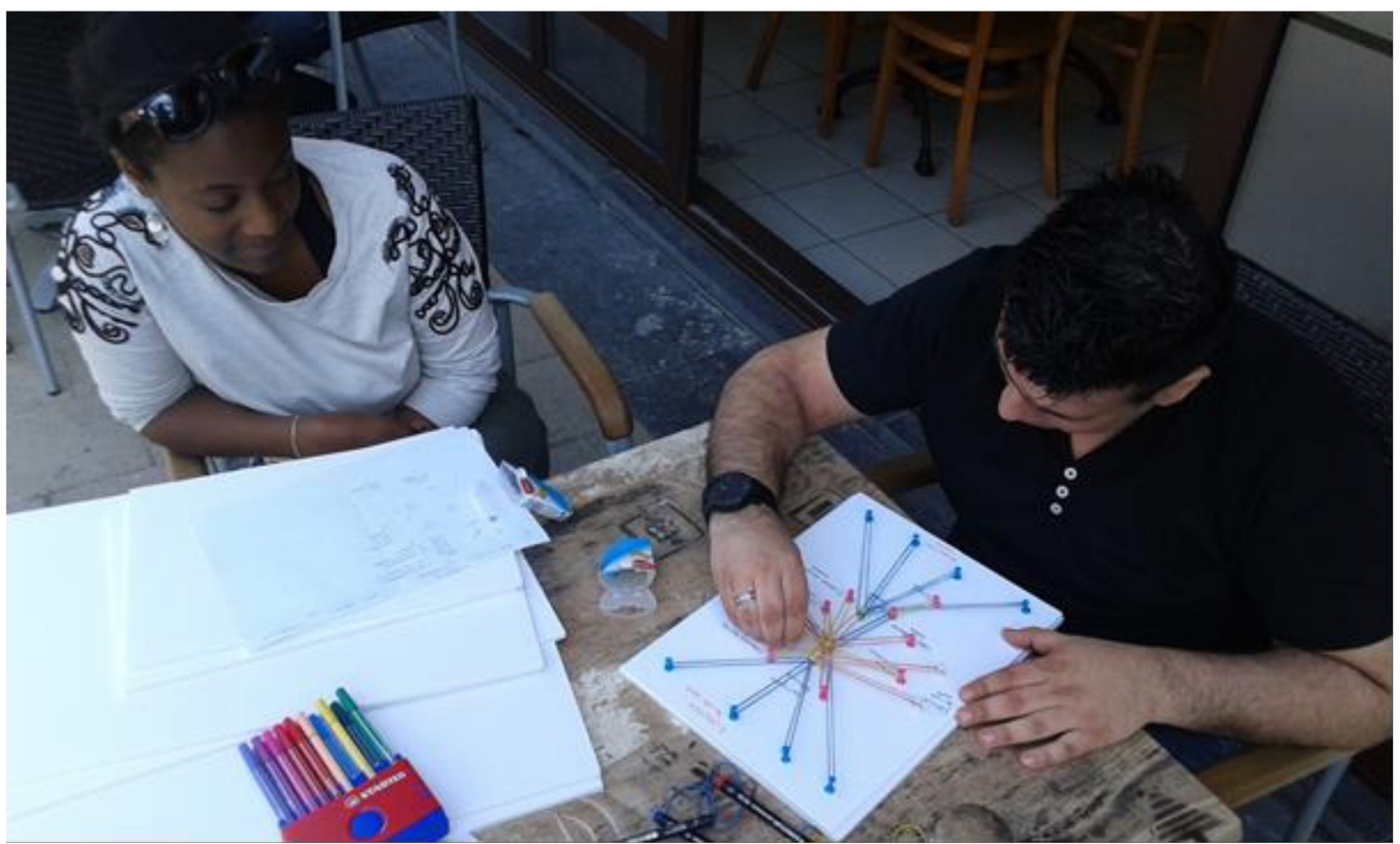

Figure 4. Mapping socio-economic networks.

\subsubsection{Knowledge}

Over three months, together with shop owners, we mapped the network of 58 shops. This strategic tool was used in one-on-one sessions where the researcher took on a passive role in assisting participants to visualize existing dynamics under the form of physical links. We opted for everyday materials in order to make the process accessible to all, as well as to establish new and creative methods of social networking examination [41]. The way proprietors choose to display their networks varies from shop to shop and outlines various types of relations and groups functioning on the street. Different types of knowledge ranging from economic to social networks came to the fore as well as the way this knowledge is distributed, and within which network. We uncovered that the administrative structure of work on Vennestraat is spread out to include individual business units and more managers in the decision-making process. This model differs from the centralized one that keeps decision-making firmly at the top of the hierarchy, such as in the mines (until the late eighties) and in the Ford Factory (until 2014).

Two types of economic flows were portrayed by shop owners: a very local and an international one. The local flow refers to small businesses on the street that rely on the products of a more established and/or larger shop to function (e.g., a bar that offers croissants from the bakery next door along with its coffee). Being a multi-ethnic entrepreneurial street, most of the shops are family businesses that sell specific traditional products which they import from their home countries. As such, their network spans from Belgium to Turkey, Italy, Morocco, Poland or Serbia. Local or international, the links uncover a clear spatial segregation phenomenon: the street is divided in two-(1) the commercial part (the segment closer to C-mine) - and (2) the rest of the street (shops further away from C-mine). Shops from the commercial part function in an almost symbiotic way while the others are self-standing and do not necessarily interact with or depend on other proprietors.

In a social dimension, most of the shops are run by and employ members of the same family. Facing the different economic shifts, shops owned by proprietors with the same cultural background formed strong associations throughout the years. This creates a clear differentiation among ethnic groups on the street leading to minor tensions and cultural clashes. Intrinsically, some groups became more visible thus gaining leverage in the dialogue with city officials and being able to impose a certain dynamic on the street (e.g., what types of activities should be organized on the street, where to place certain street furniture, etc.). Moreover, the specificity of the products placed Vennestraat on the larger map of the 
region; people traveled long distances to shop there attracted by the variety of the offer. The mapping exercise revealed that, when various activities are organized (e.g., Sunday market, food festival), the street is even attracting customers from abroad. Most of the times, these 'internationals' are linked with local customers that came to know and appreciate the diversity and mix of cultures on the street.

As such, knowledge becomes a resource which affects observable decision making. This knowledge is now trapped in a series of autonomous networks, which are oftentimes international and there is little to no exchange between these networks. To refer back to the operational question defined in chapter 2, knowledge could be redistributed when there is a constant exchange between the links of different networks. In order for this exchange to happen, knowledge must first be mapped and identified.

\subsubsection{Action}

The playful nature of the tool allowed participants to experiment and represent notions-such as economic links, social relations-that prior to the exercise were thought of only theoretically and kept them engaged throughout the whole process. The physical objects allowed them to transform a mental construction into a detailed externalization. This type of action uncovers who is involved in the production of local embedded knowledge and raises questions related to the exclusiveness of such networks shedding light on new modes of networking. The exercise equally makes room to challenge the political discourse/agenda when it comes to smaller proprietors without a strong network and their chances of survival in the street.

\subsubsection{Consciousness}

The tacit knowledge and shared learning that is embedded in local networks is key to trace and understand urban ecosystems [42,43] and gain industry 'know-how' [44]. Uncovering this knowledge requires a process of reflection among the proprietors involved in the exercise. After conducting the individual socio-network mapping sessions, a second session was organized, a group session, where participants discussed about how the physical nature of the exercise influenced their work network topology anticipation and allowed them to visualize, reflect on and understand the different dynamics they are part of [41]. This type of reflection has the potential to shape psychological and conceptual boundaries of what is possible and thus, challenge the existing power relations. Consciousness (i.e., the learning) could have been increased if we would have organized group mapping sessions. This would have allowed for a collective reflection exercise as opposed to an individual one, followed by a group discussion at a later stage, as in our case. This would have boosted learning on both sides (the researchers as well as proprietors) and therefore, could have led to a greater change to challenge the existing power relations of the context.

\subsection{Mental Images}

After mapping the socio-economic networks of the shops, we introduced a new artefact in the participatory process-mental images. We chose to introduce this new tool in order to uncover knowledge about the street dynamics from a different perspective (the perspective of passers-by) and trigger consciousness over the segregation phenomenon present in the street among proprietors. The definition of a mental images is that it "[ . . ] is a unique, personal and selective representation of reality" [45]. This emphasizes the power of the mind as it pertains to the formation of a perception about something. Mental images are purposed to project an individual's understanding or interpretation of the significance of a target urban space. Therefore, it is justifiable to argue that the manner in which a particular urban area is perceived is based on an individual's experience. Mental images explore further the foundation of one's perception of urban space, that is, whether it is a true or genuine representation of the area's social, political, geographic, and aesthetic effect. By using this tool, we engaged participants in an introspective action in order to enable them to frame personal experiences. We do so in order to identify less visible power relations and get an insight into the moments that might have influenced their appearance. As with the socio-economic networks mapping, 
we used a gamified method. We gave each participant a cardboard contour through which he/she could look at the places they were talking about and 'frame' them as a mental image (Figure 5). The discussion was structured around six main guiding questions: (1) How would you describe the street to someone who doesn't know it? what are the key characteristics?, (2) What is the story of the street: has anything changed in time? (do you remember stories/events, anecdotes about the street?), (3) Which are the most important shops (on the street) for you, in your eyes and why?, (4) What do you like? What do you dislike about the street? and (5) What would you like to see happen in the future?
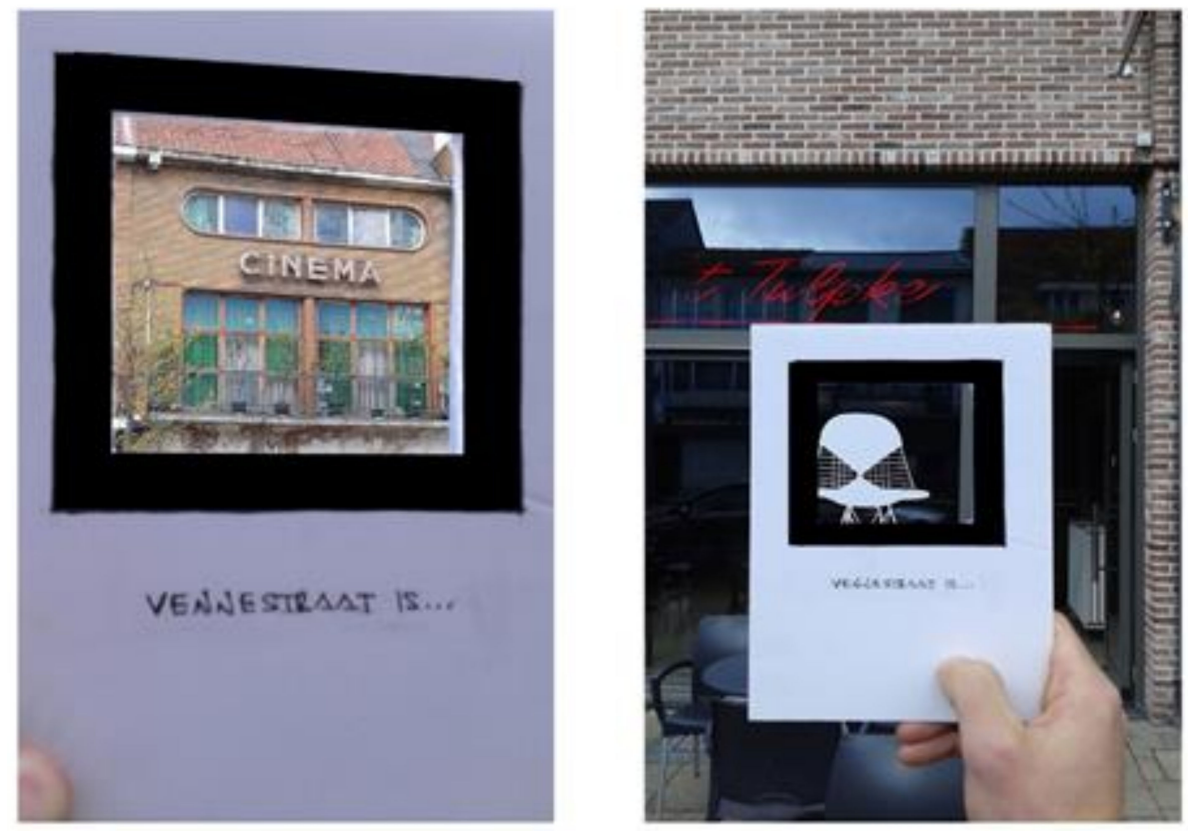

Figure 5. Capturing mental images.

\subsubsection{Knowledge}

Over four months we collected mental images from both proprietors and passers-by. Most of the passers-by that were interviewed referred back to the times when the mine was still active and the street was perceived as a dirty and dangerous place. The most iconic building on the street, that brings about a sort of nostalgia over that period, is the Cinema that stands abandoned. In the same line of thought, people relate to the C-mine, a standing ovation to the past. Although apparently very important for the dynamics of the street, C-mine is seen separate from it, both spatially and functionally. Passers-by identified the spirit of the Vennestraat street with particular shops that were on the street from 'the beginning of times' (e.g., the butcher shop, the bakery, the shoe repairing shop). The mental images people portrayed bring to the fore shops that act as mini centers of influence, attractors on the street. Here too, as with the case of the participatory method used previously, we observe a clear separation between the 'commercial part' of Vennestraat and the south part of the street, the part farther away from C-mine (Figures 6 and 7).

When asked to frame their mental images of the street, some shop owners mentioned C-mine, however, most of the proprietors related to other shops on the street. These shops are already functioning in a type of partnership. As with the mental images of passers-by, the oldest shops on the street were referred back to by proprietors. Shop owners from the south part of the street framed $\mathrm{C}$-mine and the Cinema as the main mental image they have with little to no link to the shops from the 'commercial' side. In both interviewee categories-passers-by and proprietors-we had respondents that changed their mental image during the conversation. They would then justify the shift based on additional information they had from third parties (e.g., street manager, internet, media) and had somehow overlooked or did not think about when initially framing the mental image. 


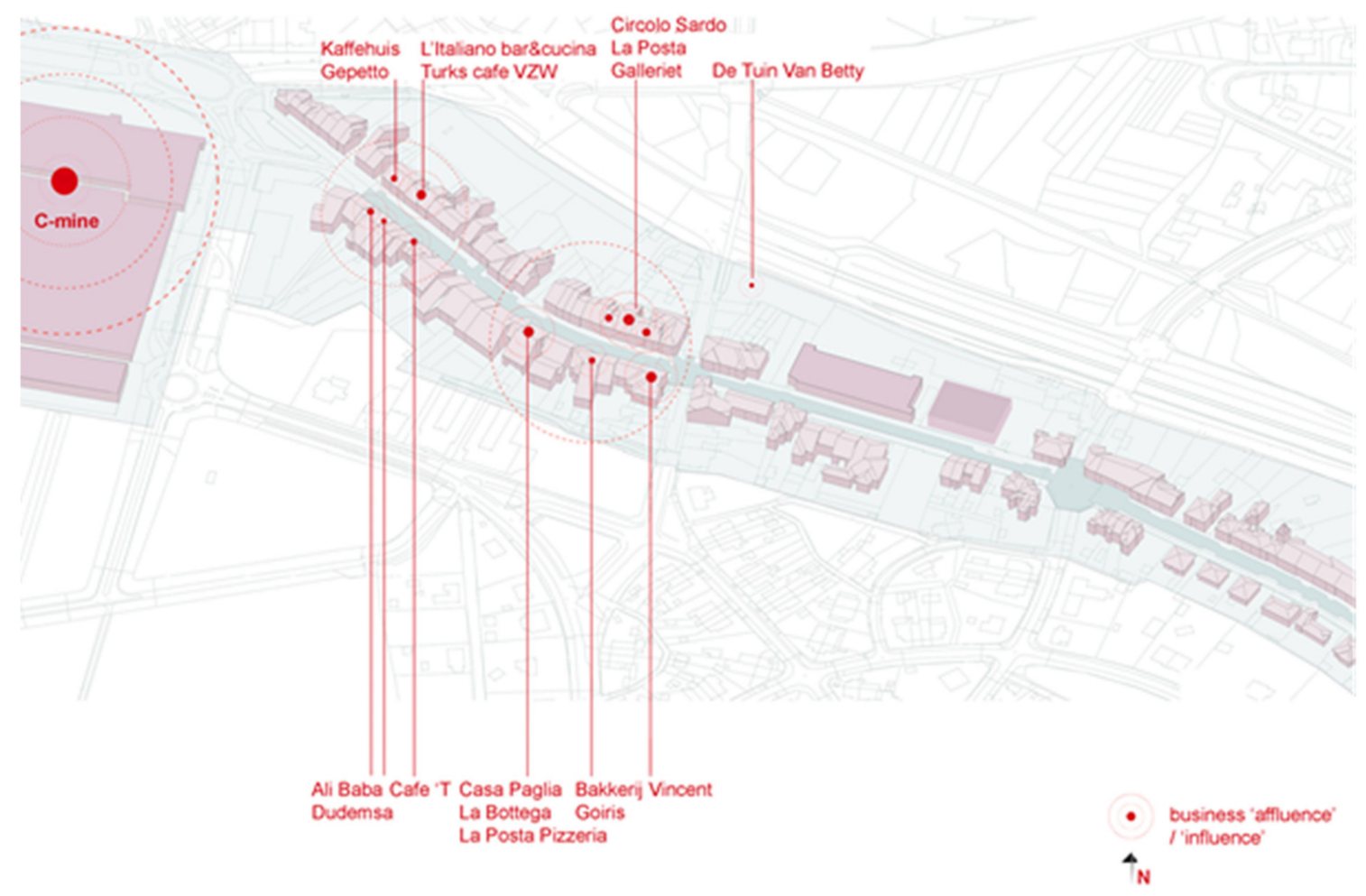

Figure 6. Intensity points on the street.

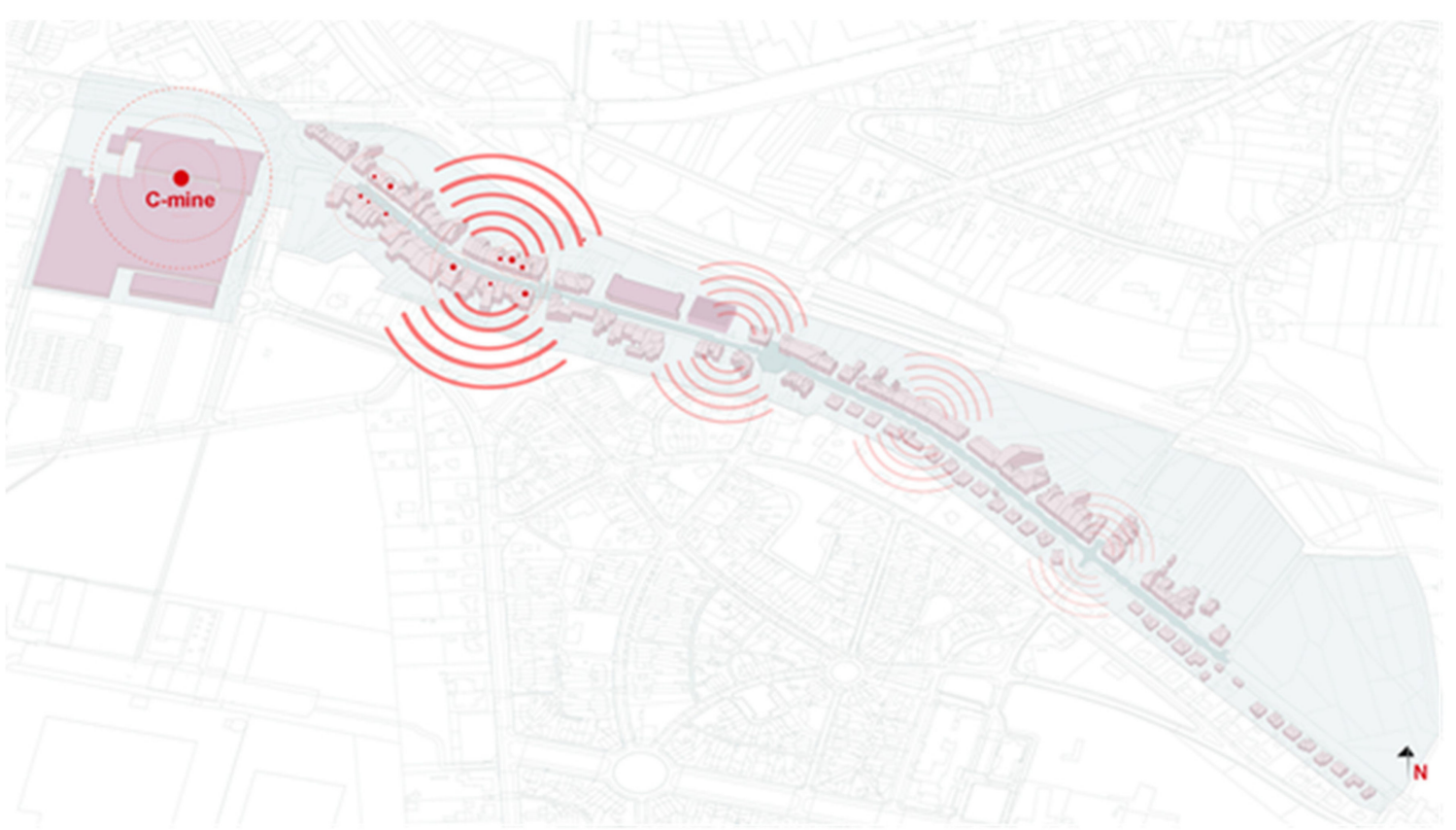

Figure 7. Business influence/affluence: representative shops.

In the case of Vennestraat, the image or reputation of the urban space is best defined through direct experiences which are quintessential in the development of an impartial evaluation of the streets' urban area. The mental images disclosed knowledge related to iconic buildings on the street (e.g., the Cinema, Vincent the butcher shop, C-mine), buildings that have an architectural and emotional value to the community (both proprietors' community as well as people visiting the street). Complementary, knowledge related to dynamics between entrepreneurs reveals micro clusters among shop owners, clusters that go beyond the economic activity mapped during the first exercise of the participatory 
process. Through mapping mental images, we acquire insight in terms of identifying the more collective carriers of urban identity alongside the general functioning of the street for particular groups. The functioning of the street is limited in that it applies for those proprietors who have similar characteristics. For instance, an areas' representation of a groups' identity is relative to their collective understanding of the carriers of the foresaid aspect. Therefore, while proprietors construct their own images based on their experiences, mapping these mental images allows for identification of points of convergence and divergence in entrepreneurs' expectations. Mental images are, in themselves, a selective instrument in that they seek to single out urban elements that play an important role in revealing the power relations that shape a participatory process.

\subsubsection{Action}

For this exercise we reached out to both proprietors and passers-by (people that use the street). We asked participants to portray the most treasured memories they have about Vennestraat, iconic moments and/or places on the street, and reasons they have to return over and over again to this space. With this tool, we took the role of observers carefully documenting the different conversations. Participants explored the possibility of articulating thoughts and lived experiences in an expressive language. The tool is tangible and creates a feeling of hands on activity making participants more relaxed during the dialogue. Both groups, entrepreneurs and passers-by, were triggered by the exercise to reflect on the potential of these images in uplifting the image of the street.

\subsubsection{Consciousness}

Every individual stores a different environmental experience in a personal, unique mental image [45]. Thus, there is need to acknowledge that a mental image "[ ... ] not only consists of direct experiences by personal use, but also aspects of personal appreciation and personal values" [45]. In this regard, the interaction with urban space is contingent on the quality of one's experience as it aligns with present expectations. In so far as the perception of Vennestraat is concerned, the complexity of mental images is yet another key insight. The selective representation of proprietors predicates the implied meaning and significance of this street. The role that direct and indirect experiences played in helping individuals form an image of the Vennestraat demonstrates that valuation is largely volatile. Therefore, personal values and experiences transcend the implied or intended effect of this space. Individuals' experiences might bring about an effect different from that anticipated. Hence, via the use of mental images, the effect of variations in the understandings of proprietors and passers-by and the recognition of 'carriers' of identity, psychological boundaries, alongside other typical characteristics of the street are made visible.

\subsection{Scenario Games}

Understanding power relations in the Vennestraat street was a three-year-long process. After experimenting with socio-economic network mapping and mental images as artefacts that engage in a participatory way with proprietors, we added a new tool. In order to dive deeper into the existing power relations, we turned to scenario games in our quest to increase the quality of a participatory process. We introduced two games (i.e., Floating City and City Makers) that were developed after a set of goals that emerged from the two previous exercises we conducted on the street to help players develop scenarios for projects. Floating City is a game-based brainstorming, discussion and problem-solving activity for small groups. It aims to foster positive thinking, the commonality between participants and provide a motivating structure for discussions that involves all participants. The game is a digital one. Such games are routinely used to help groups quickly identify significant problems with a product or service without getting too caught up with the negativity typically associated with voicing complaints. City Makers motivates participants to reflect on real life projects and understand the steps needed to carry them to completion. For a participatory process, these types of games foster interpersonal communication and knowledge dissemination about projects proposed for the street. 
Proprietors can better understand the opportunities available to get involved in the refurbishment process of Vennestraat and to develop knowledge of the existing decision-making factors. While in Floating City, a specific topic serves as a focus for collective reflection activities, City Makers take it a step further and provide insights on how one can make it possible (Table 1).

Table 1. Floating city and city makers—design goals.

\begin{tabular}{|c|c|c|}
\hline & Floating City & City Makers \\
\hline Design goals & $\begin{array}{l}\text { What collective project do we want? } \\
\text { What do we want to do together? } \\
\bullet \text { generating ideas } \\
\bullet \quad \text { explaining values }\end{array}$ & $\begin{array}{c}\text { What do we need to implement this } \\
\text { collective project? } \\
\text { - balancing individual and } \\
\text { collective goals } \\
\text { - networking }\end{array}$ \\
\hline Type of game & video game & card-based game \\
\hline Who is the game for? & $\begin{array}{l}\text { Mixed groups and/or specific groups } \\
\text { Age: } 16-60+ \\
\text { Education: } \text { mixed groups and/or } \\
\text { specific groups (low educated-higher } \\
\text { education) }\end{array}$ & $\begin{array}{l}\text { Mixed groups and/or specific groups } \\
\text { Age: } 16-60+ \\
\text { Education: mixed groups and/or } \\
\text { specific groups (low educated-higher } \\
\text { education) }\end{array}$ \\
\hline Input & $\begin{array}{l}\text { Gaming experience: low to none } \\
\text { Player brainstorms } \\
\text { - foster positive thinking, } \\
\text { commonality between participants }\end{array}$ & $\begin{array}{l}\text { Gaming experience: low to none } \\
\text { Floating City } \\
\text { - define the steps that you need to } \\
\text { implement the action }\end{array}$ \\
\hline Narrative & $\begin{array}{l}\text { - provides a motivating structure for } \\
\text { discussions that involves all } \\
\text { participants in expressing } \\
\text { shared values }\end{array}$ & $\begin{array}{l}\text { - define your own project } \\
\text { - define for yourself which } \\
\text { achievements you need to succeed in } \\
\text { this project }\end{array}$ \\
\hline Expected dynamics & $\begin{array}{c}\text { - participants interact, } \\
\text { define common values } \\
\text { - discuss issues, compare differences } \\
\text { in perspectives } \\
\text { - upon issues, react to behaviour } \\
\text { that does not comply with their norms } \\
\text { or values }\end{array}$ & $\begin{array}{l}\text { - participants collaborate over } \\
\text { particular assignments, } \\
\text { sabotaging common 'enemy', to } \\
\text { change perspectives (e.g., no longer } \\
\text { see something as a problem but } \\
\text { as a challenge) } \\
\text { - participants evaluate one's } \\
\text { action's, role, assess progress }\end{array}$ \\
\hline Expected experiences & $\begin{array}{l}\text { - collective reflection } \\
\text { - collective efficacy }\end{array}$ & $\begin{array}{l}\bullet \text { increased trust } \\
\bullet \quad \text { informing } \\
\bullet \text { collective learning }\end{array}$ \\
\hline Mechanics & collaboration & $\begin{array}{l}\bullet \text { collaboration } \\
\bullet \text { competition }\end{array}$ \\
\hline Output & $\begin{array}{l}\text { What are (collective) ambitions? } \\
\bullet \quad \text { shared norms } \\
\text { • shared success criteria } \\
\text { • a collective project (program) }\end{array}$ & $\begin{array}{l}\text { What are the chosen projects to reach the } \\
\text { (collective) ambitions/to address a } \\
\text { common challenge? } \\
\text { - alliances of players, linked to the } \\
\text { projects/resources } \\
\text { - strategies/steps/actors required to } \\
\text { implement the given project } \\
\text { - proposals for (extra) actors, } \\
\text { individual projects and } \\
\text { collective projects }\end{array}$ \\
\hline Debriefing & $\begin{array}{l}\text { - summary and comments from } \\
\text { people on the different ideas } \\
\text { - informing on what happens with } \\
\text { the collection next (follow up) }\end{array}$ & $\begin{array}{l}\text { ask players to reflect on alternative } \\
\text { projects }\end{array}$ \\
\hline Setting of the game & $\begin{array}{c}\text { living lab setting, } \\
\text { workshopslong participatory } \\
\text { processes }\end{array}$ & $\begin{array}{l}\text { living lab setting, } \\
\text { workshopslong participatory } \\
\text { processes }\end{array}$ \\
\hline Expected duration of the game & $1 \mathrm{~h}-1 \mathrm{~h} 30^{\prime}$ & $30^{\prime}-40^{\prime}$ \\
\hline
\end{tabular}

Over four months, we tested Floating City three times and City Makers twice. The playtests for City Makers revolved around how to translate ideas from Floating City, the games' mechanics and narrative while testing Floating city was about introducing the game format and understanding 
proprietors' imminent needs. Concerns about the lengthy process of the game were underlined; participants were reserved regarding the timeframe of the workshop. All playtests were organized with the help of the street manager. Except one play session, both games were tested with both shop owners association and administration representatives (the street manager). The one group-specific workshop was organized with four association members that tested City Makers. The overall dynamic of the group was shadowed by questions related to the purpose of using such tool when 'the municipality already has a good system in place that helps everyone with their business' (Dirk, shops association president). Even though the workshop was conducted only with proprietors, David (the street manager) helped us set it up. Participants made it clear they are taking part in the activity only because David asked them to. They showed little to no interest in the game and no conclusive outcome related to the prototype itself and how it could be adapted to meet their needs (apparently non-existent) was made.

\subsubsection{Knowledge}

The process of knowledge production by itself, and especially when there is involvement of people in a gathering, becomes a form of mobilization [46]. The mobilization leads to the development of new solutions and actions that are identified, tested, and retested to evaluate their significance in solving particular pitfalls that entrepreneurs experience in their day-to-day lives. Knowledge has to be embedded in the cycles involving action-reflection-action over some time [46]. Both games nurture the stated process (see Table 1), the nature of action can be made deeper and thus moves from practicality in problem-solving to more of a social transformation. The nature of the games allow shop owners to construct their own scenarios and get insight on proposed projects, the necessary steps needed to implement them and their impact. The games act as platforms of knowledge transfer between professional and entrepreneurs. Equally, there is new knowledge that emerges from the gameplay - knowledge on how proprietors understand a given project and/or proprietors' needs that are made visible by the type of scenarios they propose.

\subsubsection{Action}

We found it challenging to contact proprietors individually and organize workshops without the support of the street manager. Due to the history of research projects conducted in the area and the small 'return on investment' people received from allocating their time to such projects, as well as the lack of understanding how the process works, very few were willing to get involved. The four entrepreneurs we managed to involve in the playtests were the most active from the association and took a leading role in the decision-making process: 'Once we convince them to use the game, the rest will follow' (David, street manager). Through the power present in action, the creation of knowledge occurs, and the analysis of the new knowledge leads to the development of new forms of action. However, in our case it was difficult to activate people via this tool in its present form. This happened mainly because of the moment when we introduced it in the participatory mapping process namely, after the long break in the process when the trust level had already decreased. Nevertheless, participants were eager to understand how the games could be developed and adapted to meet their needs of punctuality. Specifically, they were curious if the games could become applications (similar to WhatsApp) that keep the main mechanics of the game and that can be used on the cell phone. This would allow proprietors to connect to ongoing debates without prescheduling a meeting making all topics available to all entrepreneurs at any given moment.

\subsubsection{Consciousness}

Proprietors we managed to interact with and bring to the playtests, including the street manager, did not see the games as a platform for dialogues between different stakeholders involved in the participatory process, offering the opportunity to articulate and rearticulate the 'voices of others' in the participatory process of further developing Vennestraat. Instead proprietors related to the games as a tool to convince the majority of 'what should be done' and what is 'the best way' to do it faster. 
Needless to say, in processes where game designers have a constant interaction with participants from the beginning of the design process, it is easier to embed participants knowledge into the game making it more appealing. However, this means elevated costs for the entire process and, as in our case, implies a degree of access to participants that, more often, we lack.

\section{Research Results}

After three years, the research conducted in Vennestraat formulated an analytical framework that operationalizes very abstract concepts—knowledge, action, consciousness—of rebalancing power relations in participatory processes. Following this type of work, portraying a set of gamified participatory artefacts and the way they complement each other becomes important to reveal the abovementioned power relations. This need motivated us to examine the existing dynamics of a decision-making process, namely the refurbishment of a commercial street in Genk (BE). By demonstrating the different tools and roles in the case study over time, we make apparent the economic, social and political dimension of the participatory process. We make no claim that this is a rigid methodology with a standard beginning and end. Instead, the framework (Table 2) shows how participants created different types of knowledge over time, appropriating differently the three artefacts: socio-economic network mapping, mental images and scenario games. Equally, we bring to the fore how each artefact can be employed in the action of producing knowledge and when we can talk about consciousness over ones' possibility to take part in participatory processes and their complex stakeholder dynamics.

Table 2. Link between knowledge, action, consciousness and socio-economic network mapping, mental images and scenario games.

\begin{tabular}{|c|c|c|c|}
\hline & $\begin{array}{l}\text { Socio-Economic } \\
\text { Network Mapping }\end{array}$ & Mental Images & Scenario Games \\
\hline Knowledge & $\begin{array}{l}\text { - } \text { economic networks } \\
\text { - } \quad \text { social networks } \\
\text { - } \text { proprietors' clusters } \\
\text { - spatial division on } \\
\text { the street } \\
\text { - ethnic clusters }\end{array}$ & $\begin{array}{l}\text { - local landmarks } \\
\text { - nostalgia over } \\
\text { specific shops/spaces } \\
\text { (e.g., the Cinema) } \\
\text { - valuation of the street }\end{array}$ & $\begin{array}{l}\text { - } \quad \text { reveal individual } \\
\text { wishes/needs } \\
\text { - collective reflection over } \\
\text { shared projects on the street } \\
\text { - identify problems/tensions }\end{array}$ \\
\hline Action & $\begin{array}{l}\text { - clear goals } \\
\text { - attention completely } \\
\text { absorbed in the activity } \\
\text { - high intensity } \\
\text { of interaction } \\
\text { - visualize abstract } \\
\text { notions/concepts }\end{array}$ & $\begin{array}{l}\text { - clear goals } \\
\text { - articulate thoughts } \\
\text { and lived experiences in } \\
\text { an expressive language }\end{array}$ & $\begin{array}{l}\text { - the activity has clear goals } \\
\text { - provide high intensity and } \\
\text { feedback } \\
\text { curiosity for participants } \\
\text { - provide a continuous sense } \\
\text { of challenge that is neither too } \\
\text { difficult as to create frustration } \\
\text { nor too easy as to be boring }\end{array}$ \\
\hline Consciousness & $\begin{array}{l}\text { - } \quad \text { reflect over } \\
\text { existing links } \\
\text { - shape psychological } \\
\text { and conceptual } \\
\text { boundaries } \\
\text { - challenge existing } \\
\text { power relations }\end{array}$ & $\begin{array}{l}\text { - individual/collective } \\
\text { carriers of urban identity } \\
\text { - understand the } \\
\text { general functioning of } \\
\text { the street }\end{array}$ & $\begin{array}{l}\text { - understand the driving } \\
\text { forces of the } \\
\text { participatory process } \\
\text { - identify all actors involved } \\
\text { in the decision-making process } \\
\text { - understand priorities }\end{array}$ \\
\hline
\end{tabular}

Knowledge, action and consciousness are discussed quite generally, mainly due to the fact that they are abstract concepts, difficult to grasp in a participatory process. As such, it is important to make efforts to clarify these terms and how they may improve participation. The artefacts we put forth-socio-economic network mapping, mental images and serious games-and their links to knowledge, action and consciousness provide some landmarks for participants and professionals dealing with the topic of making power relations in participatory processes visible. For example, taking part in the socio-economic network mapping exercise allows participants to visualize and reflect on networks and flows of people and their 
importance in an urban refurbishment project. Gathering mental images enables people to recognize values in relation to identity, landmarks and reconnect with latent knowledge over a space and/or a lived experience. Scenario games act as platforms for identifying a collective goal but need to be linked to mapping and mental image making in order to build trust. A game (to act) can never be played without developing artefacts that also support understanding and reflection over specific topics. They (games and gamified artefacts) should be one whole process that is closely linked to each other (Figure 8). In our case, the big pause between understanding (map), reflection (mental image) in the first phase and action (scenario games) in the second phase created a distance between researchers and participants, downplaying the possible benefits of playing the games.

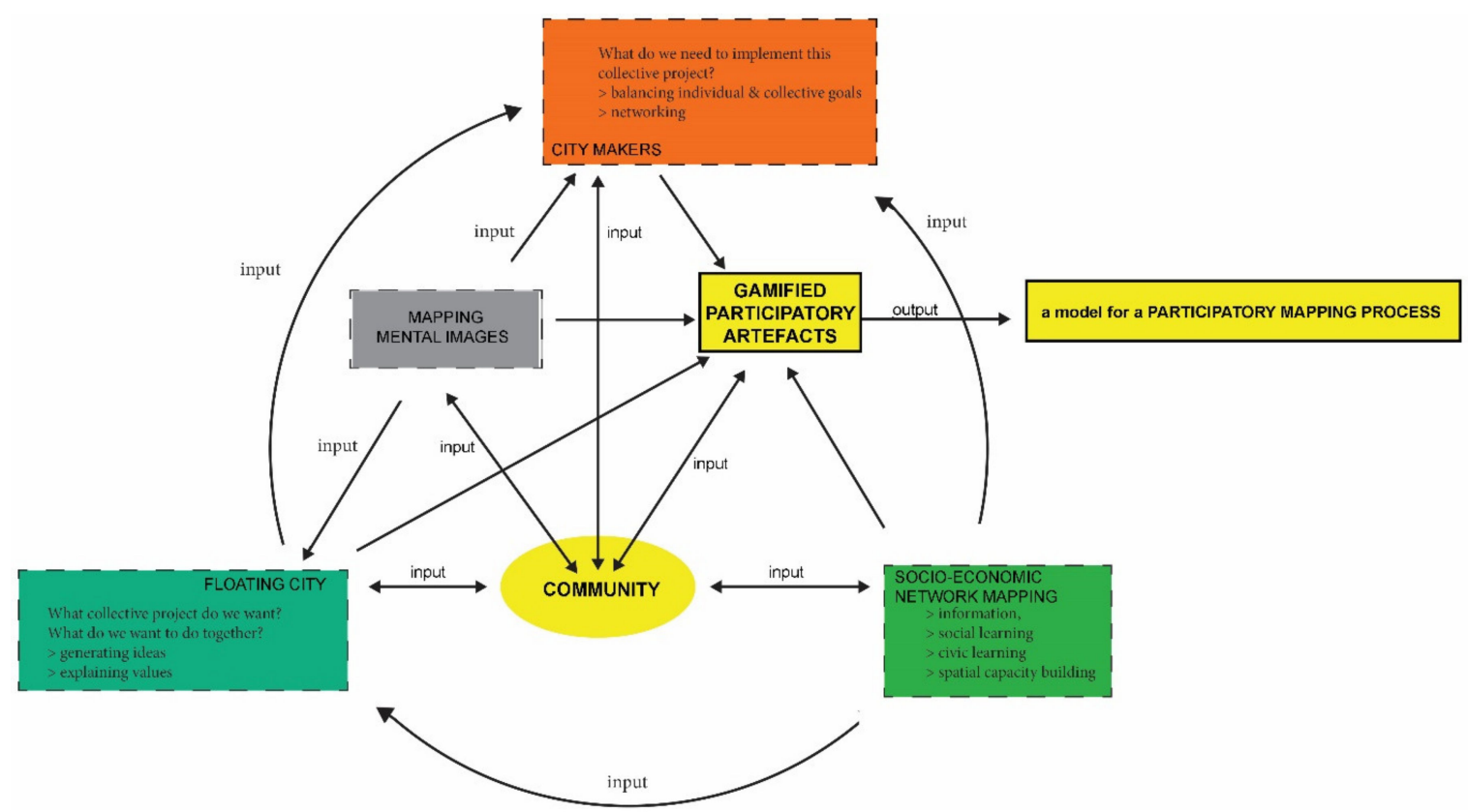

Figure 8. Dynamics of gamified participatory artefacts in a participatory mapping process.

The research strengthened our view point that, in order to design a 'good' participatory process, spatial professionals need to uncover existing power relations by employing tools sensitive to this endeavor and creating explicit links between the tools and the types of knowledge, action and consciousness they reveal. Besides the methodology, these artefacts form the backbone of a participatory process, allowing people to take part.

\section{Conclusions}

It is evident that Genk's administrative body, together with the private sector, are open to the promotion and advertisement of the city while at the same time being heavily involved in changing the morphology of the city, and in the process of creating a new entrepreneurial dynamic. As a result, Genk City Councils have succeeded mainly in changing the priorities of the planning department away from traditional concerns of local welfare and environmental stewardship towards a pro-active concern for improving the image of the city. This new dynamic has not only helped create a new external image for Genk, but it has also created a new cultural politics of place generally supportive of the city's entrepreneurial policies for Vennestraat. This social representation perspective shows the need to interpret the nature of social structures and to uncover the elusive concepts and ideas that form the basis for people's understanding of space.

We stress that it is of the utmost importance to have the recognition that reflection is directly connected to praxis and not separated from the concept. The analysis of learning involving action upon reality, the awareness of the nature of setbacks and the sources of oppression appear to change [47]. In such a case, gamified artefacts such as mapping, mental images and games could 
be used to develop participatory processes able to also engage marginalized groups. Participation, which may attract change in the knowledge of the individuals themselves, their priorities, and interests, could limit the potential impact that investigation and action can have over a defined period [48]. Participatory mapping and games as well as mapping mental images can allow participants to pay significant attention to the knowledge part of the entire equation and the action part of a participatory planning process. We emphasize the immeasurable value of social learning that the marginalized groups could obtain through the process of investigation via such gamified artefacts.

Varying levels of power in the Vennestraat street community have contributed to the access of knowledge for the different aspects of social problems and the decisions made to solve them. Notwithstanding, there exist variations in the approaches to the production of knowledge and the specific contributions of participatory planning to the process of change in society [49]. Such a view of participatory processes has aroused the interests of researchers, critiques and professionals alike regarding the role of the used method in the transformation of power relations. In this dynamic, we found gamified participatory artefacts to be useful in the knowledge production process regarding the creation of awareness and widespread action. Although we can see an increased interest in enabling tools in the decision making process of urban renewal projects, we have tried to demonstrate that socio-economic network mapping, mental images and scenario games can push the boundaries of democratic dialogue by revealing power relations in the said processes. These artefacts are good methods to ensure that multiple and 'other' voices are included in the participatory processes. However, they are best employed by people who are embedded and present in the community (e.g., neighborhood managers instead of researchers with limited presence; the demand for the app was a question in that direction) to let people take control of the process themselves during the research process.

Author Contributions: Data curation, Teodora Iulia Constantinescu; Formal analysis, Teodora Iulia Constantinescu; Methodology, Teodora Iulia Constantinescu; Supervision, Oswald Devisch; Visualization, Teodora Iulia Constantinescu; Writing-original draft, Teodora Iulia Constantinescu; Writing-review and editing, Oswald Devisch and Liesbeth Huybrechts. All authors have read and agreed to the published version of the manuscript.

Funding: Joint Programming Initiative Urban Europe: 857160.

Conflicts of Interest: The authors declare no conflict of interest.

\section{References}

1. Gaventa, J.; Cornwall, A. Challenging the Boundaries of the Possible: Participation, Knowledge and Power. IDS Bull. 2006, 37, 122-128. [CrossRef]

2. Harviainen, J.T.; Hassan, L. Governmental Service Gamification. Int. J. Innov. Digit. Econ. 2019, 10, 1-12. [CrossRef]

3. Abt, C. Serious Games; Viking Press: New York, NY, USA, 1969.

4. Duke, R. Metropolis: The Urban Systems Game; Gamed Simulations, Inc.: New York, NY, USA, 1975.

5. Constantinescu, T.; Devisch, O.; Kostov, G. City makers: Insights on the development of a serious game to support collective reflection and knowledge transfer in participatory processes. Int. J. E-Plan. Res. 2017, 6, 32-57. [CrossRef]

6. Kapp, K.M. The Gamification of Learning and Instruction: Game-Based Methods and Strategies for Training and Education; Pfeiffer: San Francisco, CA, USA, 2012; p. 18.

7. Whatmore, S.J. Mapping knowledge controversies: Science, democracy and the redistribution of expertise. Prog. Hum. Geogr. 2009, 33, 587-598. [CrossRef]

8. Devisch, O.; Poplin, A.; Sofronie, S. The gamification of civic participation: Two experiments in improving the skills of citizens to reflect collectively on spatial issues. J. Urban Technol. 2016, 23, 1-22. [CrossRef]

9. Hall, B.L. From margins to center? The development and purpose of participatory research. Am. Sociol. 1992, 23, 15-28. [CrossRef]

10. Luke, A. Genres of power: Literacy education and the production of capital. In Critical Literacy, Schooling, and Social Justice; Routledge: New York, NY, USA, 2018; pp. 161-185. 
11. Clark, W.C.; Van Kerkhoff, L.; Lebel, L.; Gallopin, G. Crafting usable knowledge for sustainable development. Proc. Natl. Acad. Sci. USA 2016, 113, 4570-4578. [CrossRef]

12. Fals-Borda, O.; Rahman, M.A. Action and Knowledge: Breaking the Monopoly with Participatory Action-Research; Apex Press: New York, NY, USA, 1991.

13. Juul, J. Half-Real: Video Games between Real Rules and Fictional Worlds, 1st ed.; MIT Press: Cambridge, UK, 2011.

14. Parlett, D. The Oxford History of Board Games; Oxford University Press: Oxford, UK, 1999.

15. Suits, B. The Grasshopper: Games, Life and Utopia, 4th ed.; Broadview Press: Toronto, Canada, 1979.

16. Jabbar, A.I.A.; Felicia, P. Gameplay engagement and learning in game-based learning. Rev. Educ. Res. 2015, 85, 740-779. [CrossRef]

17. Whitton, N. Encouraging engagement in game-based learning. Int. J. Game-Based Learn. 2011, 1, 75-84. [CrossRef]

18. Dahlgren, P. Media and Political Engagement: Citizens, Communication, and Democracy; Cambridge University Press: New York, NY, USA, 2009.

19. Schouten, B.; Ferri, G.; de Lange, M.; Millenaar, K. Games as strong concepts for city-making. In Playable Cities, Gaming Media and Social Effects; Springer: Singapore, 2017. [CrossRef]

20. Devisch, O.; Gugerell, K.; Diephuis, J.; Constantinescu, T.; Ampatzidou, C.; Jauschneg, M. Mini is beautiful: Playing serious mini-games to facilitate collective learning on complex urban processes. Interact. Des. Archit. 2018, 35, 141-157.

21. Mayer, I. The gaming of policy and the politics of gaming: A review. Simul. Gaming 2009, 40, 825-862. [CrossRef]

22. Poplin, A. Playful public participation in urban planning: A case study for online serious games. Comput. Environ. Urban Syst. 2012, 36, 195-206. [CrossRef]

23. Sweetser, P. An Emergent Approach to Game Design: Development and Play. Ph.D. Thesis, University of Queensland, Australia, 2006.

24. Fang, Y.-M.; Chen, K.-M.; Huang, Y.-J. Emotional reactions of different interface formats: Comparing digital and traditional board games. Adv. Mech. Eng. 2016, 8. [CrossRef]

25. Brian, G.; de Kort, Y.; Ijsselsteijn, W. Influence of social setting on player experience in digital games. In $\mathrm{CHI}^{\prime} 08$ Extended Abstracts on Human Factors in Computing Systems; Kientz, J.A., Ed.; ACM: New York, NY, USA, 2008.

26. Chambers, R. Back matter-Whose Reality Counts? In Whose Reality Counts?: Putting the First Last; Intermediate Technology Publications Ltd: London, UK, 1997; pp. 238-298.

27. Jordan, S.; Kapoor, D. Re-politicizing participatory action research: Unmasking neoliberalism and the illusions of participation. Educ. Action Res. 2016, 24, 134-149. [CrossRef]

28. Selener, D. Participatory Action Research and Social Change, 2nd ed.; The Cornell Participatory Action Research Network, Cornell University: New York, NY, USA, 1997.

29. Lewin, K. Action research and minority problems (1946). In Resolving Social Conflicts: Selected Papers on Group Dynamics; Harper \& Row: New York, NY, USA, 1948; pp. 201-216.

30. Harvey, D. Flexible accumulation through urbanisation: Some reactions on 'post-modernism' in the American city. Antipode 1987, 19, 260-286. [CrossRef]

31. Hall, B.L. Breaking the monopoly of action knowledge: Research methods, participation and development. In Participatory Research: Revisiting the Roots; Tandon, R., Ed.; Mosaic Books: New Delhi, India, 2002; pp. 9-21.

32. Shukaitis, S.; Graeber, D. Introduction. In Constituent Imagination: Militant Investigations, Collective Theoritization; Shukaitis, S., Graeber, D., Eds.; AK Press: Edinburgh, UK, 2007; pp. 11-34.

33. Hall, B.L. Participatory research, popular knowledge, and power: A personal reflection. Convergence 1981, 14,6 .

34. Lardier, D.T. Substance use among urban youth of color: Exploring the role of community-based predictors, ethnic identity, and intrapersonal psychological empowerment. Cult. Divers. Ethn. Minor. Psychol. 2019, 25, 91-103. [CrossRef]

35. Global Visie stad Genk 2014-2019. Available online: www.genk.be/meerjarenplanning-2014-2019 (accessed on 15 February 2020).

36. David-Vennestraat Street manager, One on one interview series conducted by the researcher in Vennestraat street, Genk, on 16 September 2018.

37. Jacobs, J. The Economy of Cities; Random House, Inc.: New York, NY, USA, 1961. 
38. Fass, J. Everybody Needs Somebody: Physical Social Networks E Visualisation; CX Program Royal College of Art Kensington Gore London, UK Arts and Humanities Research Council: London, UK, 2014.

39. Gunn, W.; Otto, T.; Smith, R.C. Design Anthropology: Theory and Practice; Bloomsbury Academic: London, UK, 2013.

40. Bagnoli, A. Beyond the standard interview: The use of graphic elicitation and arts-based methods. Qual. Res. 2009, 9, 547-570. [CrossRef]

41. Constantinescu, T.; Devisch, O. Portraits of work: Mapping emerging coworking dynamics. Inf. Commun. Soc. 2018, 21, 1263-1278. [CrossRef]

42. Ekman, J.; Amnå, E. Political participation and civic engagement: Towards a new typology. Hum. Aff. 2012, 22, 283-300. [CrossRef]

43. McRobbie, A. Clubs to companies: Notes on the decline of political culture in speeded up creative worlds. Cult. Stud. 2002, 16, 516-531. [CrossRef]

44. Conventz, S.; Derudder, B.; Thierstein, A.; Witlox, F. Hub Cities in the Knowledge Economy: Seaports, Airports, Brainports; Ashgate: Farnham, UK, 2014.

45. Sulsters, W. Mental Mapping: Viewing the Urban. Landscapes of the Mind. Available online: http: //resolver.tudelft.nl/uuid:fc71de16b4854888b6fea9d2771d9e4a (accessed on 1 March 2020).

46. Da Mota Neto, J.C. Toward a decolonial pedagogy in Latin America: Convergences between popular education and participatory action research. Educ. Policy Anal. Arch. 2018, 26, 84.

47. Jagosh, J.; Bush, P.L.; Salsberg, J.; Macaulay, A.C.; Greenhalgh, T.; Wong, G.; Cargo, M.; Green, L.W.; Herbert, C.P.; Pluye, P. A realist evaluation of community-based participatory research: Partnership synergy, trust building and related ripple effects. BMC Public Health 2015, 15, 725. [CrossRef] [PubMed]

48. Burnside-Lawry, J.; Carvalho, L. A stakeholder approach to building community resilience: Awareness to implementation. Int. J. Disaster Resil. Built Environ. 2016, 7, 4-25. [CrossRef]

49. Shardlow, S.; Aldgate, J.; Gibson, A.; Brearley, J.; Daniel, B.; Statham, D.; Doel, M. Handbook for Practice Learning in Social Work and Social Care: Knowledge and Theory; Jessica Kingsley Publishers: London, UK, 2015.

(C) 2020 by the authors. Licensee MDPI, Basel, Switzerland. This article is an open access article distributed under the terms and conditions of the Creative Commons Attribution (CC BY) license (http://creativecommons.org/licenses/by/4.0/). 